\title{
Reading Strategies in Foreign Language Academic Reading: A Qualitative Investigation
}

\author{
Rakchanok Saengpakdeejit \\ School of English, Suranaree University of Technology, Nakhon Ratchasima, Thailand \\ Channarong Intaraprasert \\ School of English, Suranaree University of Technology, Nakhon Ratchasima, Thailand
}

\begin{abstract}
The purpose of this study was to investigate how EFL undergraduate students do to improve their reading comprehension, solve the problems encountered while reading, and overcome comprehension failures. This paper presents a qualitative investigation designed to provide a clear picture of the strategies used by those students in their academic reading. A semi-structured interview served as the main source of data. Thirty-nine students from four different government universities participated in the study. The transcribed interview data was analyzed with 'open and axial coding' techniques. The data analyses revealed two main emergent categories of reading strategies: 1) strategies for comprehending reading texts (SCT); and 2) strategies for enhancing textual comprehension (SETC) with altogether 39 individual reading strategies. The implications of the findings for language teaching and learning are discussed.
\end{abstract}

Index Terms - academic reading, reading strategy, EFL undergraduate students, qualitative investigation

\section{INTRODUCTION}

This paper describes a qualitative investigation of the strategies used in the comprehension of reading English language texts when the materials being read are specialized academic reading.

Reading has been defined as the process of constructing meaning through the dynamic interaction among: (1) the reader's existing knowledge; (2) the information suggested by the text being read; and (3) the context of the reading situation (Pikulski, 1997). Brumfit (1980, p.3) has defined reading as "an extremely complex activity involving a combination of perceptual, linguistic and cognitive abilities." Moreover, Goodman (1995, p.11) has seen reading as "a psycholinguistic guessing game". He defines reading as "a communication between the reader and the writer." In this paper, reading strategies refer to any sets of learning processes, learning techniques, or learning behaviors; whether observable or unobservable, which EFL undergraduate students reported employing for comprehending an English academic reading text either in the classroom setting or outside the classroom setting including improving their reading comprehension skills, solving the problems encountered while reading, and overcoming their failures to fully comprehend the texts.

Previous research works on L2 reading have indicated that reading is an interactive meaning-making process in which readers utilize a large number of strategies to achieve the goal of reading comprehension (Alderson, 2000; Anderson, 1999; Carrell, 1998). Many researchers have begun to recognize the significant role of reading strategies in reading comprehension. Consequently, they have made attempts at identifying various reading strategies (Anderson, 1991; Block, 1986; Zhang \& Wu, 2009).

The relationship of the use of strategies to success in mastering a second or foreign language, as well as to various variables, has been the focus of a growing body of research over the past two decades (Green \& Oxford, 1995). Understanding the ways in which the strategic reading behavior of students influences reading comprehension may result in the rigorous construction of appropriate reading lessons.

In the previous studies, for example, Adamson $(1990,1991,1992)$ has found that ESL students from different academic and cultural backgrounds displayed a wide range of academic strategies. In other words, the students performed their academic reading tasks in ways they were influenced by their own academic backgrounds and culture. Their individual learning styles and the nature of the tasks assigned were also factors which could influence the students' use of strategies. According to Li and Munby (1996), they have found that ESL academic reading was a very deliberate, demanding and complex process in which the students actively invoked a variety of strategies in order to understand academic contextual materials. The students mentioned paraphrasing, repetition, using contextual clues to predict, looking for purposes and important information, visualizing, self-questioning, using background knowledge, paying attention to connectives, skimming, scanning, paying attention to topic sentences, using comparison and contrast, and picking out key words. Sheorey and Mokhtari (2001) investigated the differences in the reported use of reading strategies of native and non-native English speakers when reading academic materials. The results revealed that both US and ESL students display awareness of almost all of the strategies included in the survey. Moreover, both groups 
attribute the same order of importance to categories of reading strategies in the survey, regardless of their reading ability: cognitive strategies, followed by metacognitive strategies, and support strategies.

While such research works on L2 reading have increased interest in students' use of reading strategies, to date there has been limited qualitative research on EFL students' use of reading strategies at the university level. In academic reading, these students need to control or monitor their reading more constantly than when they read for general purposes because they might encounter difficulties while reading academic materials (Li and Munby, 1996).

\section{English teaching and learning in Thailand}

At present, the educational system in Thailand is undergoing reforms. Students learning English as a foreign language (EFL) are encouraged to be autonomous learners (Ampra \& Thaithae, n.d.). Therefore, teachers of English should implement reading strategy instruction in order to help students form good reading habits and become autonomous readers. Although readers' reading strategy use has been recognized in previous research works, very few studies in this area have been conducted in Thailand, particularly with undergraduate students.

In the Thai educational system, English is a foreign language that students must study in schools. It is a compulsory subject from the primary school onwards (Ministry of Education, 2002). Moreover, passing an English examination is a prerequisite for further education. Additionally, undergraduate students in Thailand begin reading lengthy and authentic academic texts starting from the second year of their study. In spite of the importance of English reading, Thai students' reading proficiency is low because of the limited use of English in the students' day to day life. According to Silapasatham (1999), the teaching and the learning of languages in the Thai education system is in crisis because a great number of university graduates cannot use English effectively.

Since many universities benefit from academic materials written in English, English reading proficiency becomes an extremely important requirement for the students. The students are expected to understand what they read regardless of the subject matter they study. Therefore, reading skills are of significant importance in such environments (Ozek 2006). With strengthened reading skills, EFL students will make greater progress and attain greater development in academic areas. As the ability to read an academic foreign language text is difficult, complicated and time-consuming, any strategies that may make academic reading easier have been the subject of much interest.

Hence, this study aimed to produce the data that would contribute to better understanding of EFL academic reading and that would provide useful information for both EFL instructors and EFL students about the nature of EFL academic reading comprehension. By exploring the students' use of reading strategies, the present study may give direction for teaching and learning. Moreover, it may aid teachers in selecting appropriate course materials for their students. In addition, the findings of this study are expected to generate some implications for EFL reading lesson in universities in Thailand. This study was also expected to find answers to the following two research questions in the context of students' use of reading strategies while reading academic texts (such as reading textbooks, journal articles, class handouts, etc.):

1) What strategies do EFL students use to achieve comprehension in their academic reading? and

2) How do they use these strategies?

\section{MEthodology}

\section{A. Participants}

A total of 39 EFL undergraduate students from four government universities in four different regions of Thailand participated in the study. At the time of data collection, the participants were enrolled in either ESP or EAP courses. All of these 39 students were willing to participate in the study. Although no specific criteria were used to select these 39 participants, they had to come from either the field of Health Science or Science and Technology. Within this group, there were 23 Science and Technology students, and 16 Health Science students. These students were chosen as the subjects of this study because they had to read a lot of academic texts related to their field of study. Color figures will be appearing only in online publication. All figures will be black and white graphs in print publication.

\section{B. Data Collection}

A semi-structured interview was used as the main instrument for data collection of the present study in order to elicit information about reading strategies employed by the participants. It is regarded as one of the most powerful ways that researchers employ to understand others (Punch 2005). One of the advantages of semi-structured interview is that interviewer can make clear the questions that are ambiguous to interviewees. The reason for its popularity is stated by Nunan (1992) “... because of its flexibility, the semi-structured interview has been found favour with many researchers, particularly those working within an interpretive research tradition". In the semi-structured interview, the interviewer has a general idea of where he or she wants the interview to go, and what should come out of it, but does not enter the interview with a list of predetermined question (Nunan, 1992). The interviewer used a list of questions as guidelines rather than specific questions worded identically for each participant.

To explore how the participants manage their academic reading texts, a one-to-one semi-structured interview was conducted as the main method of data collection. With respect to the student interview question guide, it comprised altogether 13 questions. There were two main parts in the interview. The first part of the interview (Questions 1 to 4) was concerned with gathering basic information about the interviewees. This part was intended to (1) develop a good 
relationship and trust between the interviewer and the interviewees; (2) increase the interviewees' confidence in the interview scenario; and (3) reduce the interviewees' nervousness in the interview environment (Measor, 1985 cited in Intaraprasert, 2000). The second part (Questions 5 to 13) focused on the students' reading strategies employed both inside and outside a language classroom. The main purposes of this part were to explore the students reading strategies they used while reading academic texts, the problems the students encountered while reading, and how they solved those problems. The questions used in the investigation can be summarised as follows:

Part I:

Q1: a general introduction to the interview including; the interviewer's and interviewees' names, the interviewees' area of study and the purposes of the interview;

Q2: an investigation of the number and level of English courses that each interviewee is studying or has already studied;

Q3: an investigation of the number of hours per week that each interviewee is spending, or has spent studying English, and whether he or she considers it to be sufficient;

Q4: an investigation of the number of hours per week that each interviewee is spending, or has spent attending EAP or ESP classes and whether he or she considers it to be sufficient;

Part II:

Q5: an investigation of each interviewee's perception of his/her reading ability

Q6 and Q7: an investigation of each interviewee's opinion about the importance of English academic reading in his/her life, and future career;

Q8: an investigation of each interviewee's opinion about what he/she finds difficult in English academic reading;

Q9: an investigation of reading problems each interviewee encounters while reading English academic material, and how he/she solves those problems;

Q10: an investigation of each interviewee's strategies that he/she employs to discover the meanings of unknown vocabularies;

Q11 and Q12: an investigation of the student's use of reading strategies both within and outside the classroom settings (pre-reading, while-reading, and post-reading); and

Q13: an investigation of each interviewee's opinion about reading study from his/her own experience.

Both interviewer and all interviewees agreed to speak Thai during the interviews so that the participants, whose native language was Thai, would not misinterpret or misunderstand the questions which might distort the actual responses. The interviews were held during the first semester of the 2008 academic year and the average length of each interview was about 30-40 minutes. Each interviewee's appointment was arranged at a time that was convenient for them to attend the interview. The participants were told that the researcher was interested in how EFL undergraduate students, whose native language is Thai, achieve comprehension when reading academic materials. At the beginning of the interview session, each interviewee was requested to choose and read one academic passage. Reading materials varied from required textbooks, journal articles, and articles recommended by his/her instructor. In each interview, the interviewer silently read a copy of the material as the interviewee read. Reading averaged 15 minutes. The interview started after both the interviewer and the interviewee had finished reading the passage. While interviewing, the researcher tried to establish a relaxed atmosphere and to develop a good relationship between the interviewer and interviewees by addressing the students by their first name, or nickname based on their preference. In the interview, the participants were requested to answer and talk to the researcher about how they managed to achieve comprehension while reading academic texts, especially an understanding of those parts of the text which they found particularly difficult. The researcher started the interview by talking about the background information of the interviewees, such as their names, major field of study, etc. They were then asked to identify any problems found while reading and how they solve those problems and achieve comprehension. Moreover, their responses guided the subsequent questions for the interview. For example, when unfamiliar vocabulary items were mentioned as being the difficulty in comprehending and understanding a particular text, the issues would be discussed including the ways in which the students solved and overcame that difficulty.

All interviews were tape-recorded instead of taking notes. According to Intaraprasert (2000), taking notes while conducting the interview can interrupt the interview process and eventually it may result in the failure of the interviews. Then, all recordings were transcribed more or less verbatim after having finished interviews. Two strategies were used in order to increase the reliability and validity of the interview transcripts after having finished the first transcribing: 1) repeatedly listening to and transcribing the tape records of the interviews with two colleagues; and 2) equating the literal meanings of transcripts through back-translations by asking for assistance from friends who are university instructors.

\section{Data Analysis}

The transcribed interview data were analyzed with 'open and axial coding' techniques proposed by Punch (2005) and Strauss and Corbin (1998). According to Strauss and Corbin (1990 and 1998), coding serves to summarize, synthesize, and sort out the emergent themes in interviews. Strauss and Corbin (1998) have defined Open coding as "the analytic process through which concepts are identified and their properties (the general or specific characteristics or attributes of a category) and dimensions (the location of a property along a continuum or range ) are discovered in data" and Axial 
coding as "the process of relating categories to their subcategories, termed "axial" because coding occurs around the axis of a category, linking categories at the level of properties and dimension." For qualitative researchers, coding means creating categories from interpretation of the data and examining the pre-formed categories based on the purpose of the investigation. In the present study, the data collected for this study were analyzed through Open coding, i.e. process of breaking down, examining, comparing, conceptualizing, and categorizing data (Strauss and Corbin, 1990 and 1998) in order to take the data obtained apart and to examine the discrete parts for difference and similarities, moreover the axial coding was used in order to reassemble the data fractured during open coding. Then, the researcher carefully read the transcripts for possible codes or categories relevant to the purposes of the study. Initially, hundreds of strategies emerged from the interviews. Thus, these strategies were as far as possible summarized and grouped. Many of the reported reading strategies frequently mentioned by the participants were consistent with other research findings, e.g. use of background knowledge, context clues, translation, prediction, and so forth. However, three reading strategies reported by the participants were singled out because they were not specifically mentioned in any past research findings. These included looking for the parallel article(s) in Thai (if any), reciting vocabulary items in rhymes, and associating the sound of a Thai word with that of a new English vocabulary item. The reading strategies were then categorized based on the definition of reading strategies for the present study mentioned earlier. Categorized data were checked by the researcher's supervisor and three other colleagues.

\section{RESULT}

The data showed that the participants actively invoked a variety of strategies in order to achieve the academic reading texts. The analysis of the data revealed a total of 39 statements which the students reported employing while reading an English academic material. Then the 39 statements were classified into two main categories: 1) strategies for comprehending reading texts (henceforward "SCT"); and 2) strategies for enhancing textual comprehension category (henceforward "SETC"). A brief description of each category and the number of items within each category are given below:

Category 1: Strategies for comprehending reading texts (SCT) refer to the actions and procedures that the reader employs when faced with academic reading materials (28 items). This category has been abbreviated as SCT in order to apply a structure and reference system to the data. The strategies in this category can be divided into three purposes as follows:

Purpose 1: To comprehend reading texts before doing the actual reading

(SCTBAR) or pre-reading strategies are techniques which the students reported employing to comprehend the academic text before doing actual reading. The interview data revealed that the participants reported eleven strategies running from SCTBAR1 to SCTBAR 11 which were employed before starting reading. These strategies might aid them to get some information about what they were going to read. Furthermore, the interview data showed that the participants generally felt a lot of anxiety about academic reading because they were not capable of comprehending directly in texts written in English. Before reading, they needed to know something appeared in the texts, therefore the participants depended heavily on the BAR strategies. While reading something "for fun", they might not rely on BAR as much as they did with the academic reading. The eleven BAR strategies include:

SCTBAR 1: Looking for unfamiliar vocabulary items and searching for their meanings

SCTBAR 2: Reading the title of the text

SCTBAR 3: Going through the text quickly (Skimming)

SCTBAR 4: Reading the first and the last paragraphs

SCTBAR 5: Looking at pictures/charts/tables/figures that appear in the text

SCTBAR 6: Looking at questions about the text (if any)

SCTBAR 7: Scanning for main ideas

SCTBAR 8: Thinking of one's background knowledge about the text

SCTBAR 9: Reading the abstract or introductory part

SCTBAR 10: Looking for the parallel article(s) in Thai (if any)

SCTBAR 11: Predicting what might happen in the text

The examples of students' statements are as follows:

"I will look roughly through the whole passage, text, etc. which I am going to read for new words and underline them. Then I will look them up in a dictionary."

"I will glance through the text in order to check how many new vocabulary items appear. Then I will list all of them and look for their meanings. If I cannot discover the meaning of the vocabulary from my colleagues I will look up the meanings in a dictionary."

"I will read the title of the article in order to imagine what happens and think whether or not I already have some knowledge of that particular topic"

"I sometimes ask myself questions about the text based on its title, prior to my reading of the article. I will then try to answer my predicted questions"

"For my study, I have to read a large number of articles. When reading each text I begin by reading its abstract in order to discover what the article is generally all about." 
For this purpose, the most frequently found strategy being reported was that the students looked for unfamiliar vocabulary items and then searched for their meanings (SCTBAR 1). This was followed by the use of background knowledge (SCTBAR 8). This showed that for this group of students, the problem of vocabulary seemed the most serious. Most students reported employing dictionaries as the main instrument in searching for meanings. A large number of theories and research findings have emphasized the importance of using background knowledge in English reading. Li and Munby's study indicated that the participants gave much credit to the use of background knowledge in their L2 academic reading. They believed that background knowledge of the content was extremely important for reading and that lack of relevant background knowledge impeded their reading comprehension.

Although the participants believed that deficiencies in the use of SCTBAR strategies might impede their reading comprehension, they realized that these strategies were not necessarily effective at all times because in some situations such as in the examination, there was not enough time for pre-reading. The participants also realized that reading strategies were very useful and could help them in the process of academic reading comprehension, but they said that they did not receive any formal training in how to use strategies at school.

Purpose 2: To comprehend reading texts while doing the actual reading (SCTWAR) or while-reading strategies are the actions and procedures readers use while working directly with the academic text. The students reported employing a range of specific strategies in order to understand and fully comprehend the academic text that they were reading. Eleven strategies running from SCTWAR1 to SCTWAR 11 emerged from the interview. The interview data revealed that the participants also depended heavily on the WAR strategies. Clearly the participants realized that the use of these emergent strategies played a very important role in reading. As EFL learners, they believed that they always employed at least one WAR strategy not only in reading academic materials, but also non-academic materials. These eleven strategies include:

SCTWAR 1: Searching for the meanings of unfamiliar vocabulary items

SCTWAR 2: Analyzing a sentence structure

SCTWAR 3: Taking notes of the important information

SCTWAR 4: Guessing the meaning(s) of the sentence(s) from the context

SCTWAR 5: Rereading certain part(s) of the text

SCTWAR 6: Reading certain part(s) of the text slowly

SCTWAR 7: Skipping difficult part(s)

SCTWAR 8: Highlighting important information or difficult vocabulary items by underlining

SCTWAR 9: Highlighting important information or difficult vocabulary items by making symbol(s)

SCTWAR 10: Translating the reading text into the student's first language

SCTWAR 11: Making a summary of certain part(s) of the reading text in either Thai or English, or both

Some students' statements are shown below:

"Although I have already looked up the meanings of difficult words before starting reading, I will consult a dictionary again if I face new words while reading."

"If I have found some difficult parts while reading, I will try to read the whole text continuously. Then I will understand what I have read by predicting the meaning of the text from the context."

"I often ignore the difficult parts of a particular text if I can't predict the meaning of that section from the context. Later I will re-read that section in order to confirm my understanding."

"I will try to make myself understand the article by translating the text sentence by sentence-I feel that I have to use this technique in order to understand the reading. When finishing each sentence, I will take a note of the translation. After finishing the whole text, I will attempt to understand the text by linking every sentence together."

As mentioned above, the participants reported using at least one SCTWAR strategy in either their academic or nonacademic reading. The most favored or most often reported strategy being used was searching for the meanings of unfamiliar vocabulary items (SCTWAR 1), and followed by translating the reading text into student's first language (SCTWAR 10), skipping difficult part(s) (SCTWAR 7), and guessing the meaning(s) of the sentence(s) from context (SCTWAR 4). This finding was emphasized by these students having stated that unfamiliar vocabulary items were the most serious problem in the lack of understanding of academic reading texts.

Translating what is read in L2 into L1 is a unique strategy for L2 readers who use their first language as a base for understanding or producing the second language (O'Malley and Chamot, 1990). Although some students reported that they had obtained high scores in English proficiency test, they still reported employing translation as a strategy to overcome their academic reading tasks. Many participants reported that they often translated individual words into Thai. Furthermore, the interview data revealed that a lot of participants were unable to think directly in English when reading an English academic text. Instead, they read in English and tried to look for the meanings of unknown words in Thai. Then they thought about what they had read in Thai. The participants also reported that they did a lot of translating when they read English text, then they translated each word of the sentence into Thai and wrote the Thai words above, below, or next to the English sentence in the text. This can be concluded that the students depended heavily on the translation process.

Many of the participants agreed to skip some difficult parts they encountered while reading. They reported that they did not want to waste a lot of time on those parts which could be skipped over without losing much comprehension. 
Furthermore, the students skipped the unknown words that were considered not essential to overall comprehension. The participants said that sometimes after having finished reading, they would ask their friends or instructors to make sure their comprehension of the whole text was accurate after skipping some parts.

$\mathrm{Li}$ and Munby (1996) found that the participants of their study were capable of using context clues to predict unfamiliar words or phrases in the texts being read. They tried to predict the meanings of the words or phrases by examining their relationship with other items in the sentence. In the present study, the participants reported that they were always encouraged to use context clues to predict the unknown words found in the texts but they did not receive any intensive training at school. Therefore, they often failed in predicting the meanings of unknown words using this strategy. The interview data also revealed that using context clues to predict the meanings of the words was one of the most favored reading strategies, though most of the predictions were incorrect. The participants said that sometimes after the predictions, they would look up the meaning of the words in the dictionary to make sure their predictions were accurate. However, the students frequently found that their predictions were proved wrong. Therefore, they preferred to skip words that were considered difficult and not significant to the understanding of the entire text instead of predicting the meanings of words using context clues.

Purpose 3: To comprehend reading texts after having done the actual reading (SCTAAR) or post-reading strategies are actions or techniques which the students reported employing to make sure of their understanding after they have finished reading. These strategies are intended to aid the reader in comprehending the text after they have finished reading such as using some methods to search for the meanings of unknown words which were ignored while reading, discussing what was read with colleagues, or preparing a summary of what was read. Six strategies running from SCTAAR1 to SCTAAR 6 emerged from the interview. The interview data showed that the only half of the participants reported employing some strategies after finishing reading. In other words, the participants did not depend heavily on SCTAAR strategies. In reading something for fun, they reported not to use any strategies after reading. These six SCTAAR strategies are:

SCTAAR 1: Searching for the meanings of new vocabulary items skipped while reading

SCTAAR 2: Discussing the reading text with classmate(s) or friend(s)

SCTAAR 3: Making a summary of the whole reading text

SCTAAR 4: Retelling oneself or other people about what has been read

SCTAAR 5: Reviewing one's own notes

SCTAAR 6: Translating the reading text into Thai using Thai script

Some reported statements are shown below:

"After reading, I will reread the unknown words that have been found while reading. Then, I may look for the meanings of those unknown words that I have skipped over while reading using the dictionary or asking other people after reading."

"I like to talk with my friends after finishing reading. If I can't understand some parts, my friends can help me. On the other hand, I can try to explain the part on which they aren't clear."

"After I have finished reading in English, I translate the whole text into Thai. I have to use this technique in order to check how much of what I have just read I can understand."

Although many participants did not rely heavily on SCTAAR strategies, six strategies were still reported to be employed after reading. Again, the finding has emphasized that the most serious problem reported by the participants in academic reading has been the problem of unfamiliar vocabulary items. Therefore, searching for the meanings of new vocabulary items skipped while reading (SCTAAR 1) was reported to be employed the most frequently. It is followed by discussing what was read with the participants' classmates or friends (SCTAAR 2), and making a summary of what was read (SCTAAR 3).

Some participants reported that they were likely to talk and discuss what was read with their friends in order to check their understanding. While discussion, they shared their ideas of what they read. They compared the similarities and the differences between their understanding so that they did not misunderstand the context. Many participants added that when they could understand the text, they listed the important points into their notebooks and make a summary of what they read. Then they would be able to review it many times without reading the whole text.

Category 2: Strategies for enhancing textual comprehension (SETC) are mechanisms to help the reader in understanding new vocabulary items found while reading (11 items). The strategies in this category can be divided into two purposes as follows:

Purpose 1: To enhance textual comprehension by solving problems dealing with unknown vocabulary items (SETCUV)

From the interview data, for most of the participants who were EFL students, the major problem in academic reading was the words which they did not know the meanings. They reported that they always suffered from deficiencies at the number of English vocabulary items which have influenced their reading comprehension. The interview data revealed that the participants reported five strategies running from SETCUV1 to SETCUV5 which were employed when they encountered unknown words while reading. They realized that the use of these emergent strategies played a very important role in reading. These strategies may aid them in comprehending what they were reading more easily. 
As EFL learners, the participants believed that they always employed at least one strategy to aid them to know the meanings of unknown words not only in reading academic materials, but also non-academic materials. These emergent five strategies include:

SETCUV 1: Guessing the meaning of a new vocabulary item from the context

SETCUV 2: Looking at the root of an unknown vocabulary

SETCUV 3: Looking up the meaning of an unknown vocabulary item from electronic resources e.g. electronic dictionary (Talking dictionary), dictionary program in a computer, and the Internet

SETCUV 4: Looking up the meaning of a new vocabulary item in a dictionary either English - English or English Thai

SETCUV 5: Asking for assistance

For example,

"While taking a reading test, I often encounter the problems of unknown vocabulary items. What I usually do is to predict the meanings of those words using the context."

"I sometimes predict the meaning of new vocabulary items from their roots."

"Normally I take my talking dictionary with me to the reading class because I know that I can't read any English texts without knowing the meanings of vocabulary items. Therefore I always consult the talking dictionary....I also look up the meanings of unknown vocabulary items on the internet when I work in front of the computer."

"I always use a dictionary whenever I encounter new vocabulary items. I always look those words up in the dictionary as I believe that it is important not to ignore new vocabulary items."

"I may ask my teacher for the meanings of unknown words if they are technical words which can't be looked up from a general dictionary."

In this study, the participants depended heavily on their knowledge of vocabulary because they wanted to understand what they read. They also reported that they did not think reading was difficult if they knew the meaning of every word in the text. Therefore, they always employed some strategies to establish the meaning of every unknown word from the text. Unfortunately, they often employed ineffective strategies, e.g. predicting the meaning of unknown words from the context and often missing some important information. Thus, the strategies which the participants relied heavily on were looking up the meanings of unknown words from either electronic resources or normal dictionary which could always give them the correct definitions.

Purpose 2: To enhance textual comprehension by retaining knowledge of newly-learned vocabulary items (SETCRV)

SETCRV strategies are the actions and procedures the students employ after having learnt new vocabulary items in order to retain meanings of those items. Such strategies include:

SETCRV 1: Using new vocabulary items to converse with classmates and friends

SETCRV 2: Learning the meanings of new words by rote

SETCRV 3: Reciting vocabulary items in rhymes

SETCRV 4: Associating real objects with vocabulary items

SETCRV 5: Associating the sound of a Thai word with that of a new English vocabulary item

SETCRV 6: Tutoring one's classmate(s) or friend(s) the reading lessons

Some reported statements are shown below:

"I believe that after I know the meanings of new vocabulary items. If I use those words often in my daily life, I will become familiar with them and finally I will be able to remember them. I also try to talk with my friends by using the newly-learned words in our conversations."

"While reading, I always look some unknown words up in the dictionary. This can help me understand what I read....After knowing the meanings of those words, I try to memorize their meanings."

"After class, I usually write new vocabulary items that I have learnt in the lessons on pieces of A4 paper and stick them on the wall in my bedroom. I look at and memorize them when I walk pass. This can help me remember their meanings."

Most students reported not to rely heavily on these strategies. Although the interview data showed that the participants did not employ these strategies often, they realized that these strategies played a very important role in reading, especially academic reading. The purpose of these strategies is to expand and to retain the students' knowledge of English vocabulary. The most favored or most often reported strategy being used in order to retain the meaning of an unknown word was learning the meanings of new words by rote (SETCRV 2), and this was followed by using new vocabulary items to converse with classmates and friends (SETCRV 1). 
TABLE 1

DESCRIPTION OF RESEARCHER-CONSTRUCTED THE READING STRATEGY CLASSIFICATION

\begin{tabular}{|c|c|c|}
\hline \multicolumn{3}{|c|}{ Reading Strategy Inventory (RSI) } \\
\hline Main Category & Purpose to be Achieved & Individual Strategy \\
\hline \multirow{3}{*}{$\begin{array}{l}\text { Main Category } 1 \\
\text { Strategies for } \\
\text { comprehending reading } \\
\text { texts (SCT) }\end{array}$} & $\begin{array}{l}\text { - To comprehend reading texts before doing the actual } \\
\text { reading (SCTBAR) }\end{array}$ & SCTBAR 1 - SCTBAR 11 \\
\hline & $\begin{array}{l}\text { - To comprehend reading texts while doing the actual } \\
\text { reading (SCTWAR) }\end{array}$ & SCTWAR 1 - SCTWAR 11 \\
\hline & $\begin{array}{l}\text { - To comprehend reading texts after having done the } \\
\text { actual reading (SCTAAR) }\end{array}$ & SCTAAR 1 - SCTAAR 6 \\
\hline \multirow{2}{*}{$\begin{array}{l}\text { Main Category } 2 \\
\text { Strategies for enhancing } \\
\text { textual comprehension } \\
\text { (SETC) }\end{array}$} & $\begin{array}{l}\text { - To enhance textual comprehension by solving problems } \\
\text { dealing with unknown vocabulary items (SETCUV) }\end{array}$ & SETCUV 1 - SETCUV 5 \\
\hline & $\begin{array}{l}\text { - To enhance textual comprehension by retaining } \\
\text { knowledge of newly-learned vocabulary items (SETCRV) }\end{array}$ & SETCRV 1- SETCRV 6 \\
\hline
\end{tabular}

\section{DisCUSSION}

The data of this study clearly shows that the participants had an awareness of their activities while reading English academic materials. The information provided by 39 participants revealed that English academic reading in the tertiary level was a complex process in which they consciously employed the number of strategies. They employed these strategies in order to comprehend an English academic text by improving their reading skills, solving the problems encountered while reading, and overcoming reading comprehension difficulties. This study is significant because it provides a detailed account of the reading strategies reported to be employed by the participants in their English academic reading. It may provide empirical support for future study on reading strategies.

Generally, all participants demonstrated a reliance on dictionaries both electronic dictionaries and book dictionaries in attempts to comprehend English academic text. This strategy has been identified as characteristics of less skilled readers (Bang and Zhao, 2007). Therefore, the finding revealed that most students could be classified as less skilled readers because they relied heavily on dictionaries. Contrastingly, some participants reported employing contextual clues, discussion with classmates and friends, and help of peers or teachers as ways of achieving comprehension of English academic texts, all of which have been recognized as habits of more skilled reader (Bang and Zhao, 2007).

The interview data revealed that the participants were able to monitor the use of reading strategies according to how much they could understand the text and how difficult the texts were. As has been mentioned earlier, the participants customarily used various strategies to help them understand the texts. For example, some were using contextual clues, use of background knowledge, asking for assistance and translation which were consistent with the previous studies from many researchers (e.g. Block, 1986; Sheorey and Mokhtari, 2001; Lau, 2006; and Bang and Zhao, 2007). Reading strategies have played an important role in students' academic reading comprehension, and those strategies will not necessarily be the same as those employed by native English speakers, since EFL students can draw on their native language and on strategies they have developed in their own countries (Adamson, 1991).

Based on the findings of this study, emergent tactics for overcoming English academic reading materials can be classified into 2 groups: 1) strategies for comprehending reading texts (SCT); and 2) strategies for enhancing textual comprehension (SETC). In classifying reading strategies for the present study, it was remarkable that the reading strategies in both categories always support each other. That is, the strategies which students reported employing in order to deal with unknown vocabulary items may help them improve their reading skills in general. In the same effect, the actual reading strategies which students reported employing to comprehend an academic reading text may help them discover the meanings of new vocabulary items. That is, the reading strategies under the two main categories have a spiral relationship rather than linear.

The most obvious implication of this study for EFL instruction derives from the findings that the most serious problem found while reading English academic material may be the problem of unknown vocabulary items. In other words, the students' serious problem is lack of knowledge of English vocabulary. This suggests that due to the demanding nature of vocabulary learning, the teaching of vocabulary may not be productive. Moreover, the findings revealed that the strategies taught in English classes may not be adequate to apply in English academic reading. Carrell (1991) has pointed out that effective language reading pedagogy must include not only training and practice in the use of strategies, but more importantly, information about the significance and outcome of these strategies and the range of their utility. EFL instructors should provide their students knowledge of strategy use and then encourage them to use the strategies while reading. This is according to Grabe (1991), and Bang and Zhao (2007), readers have to employ a wide range of strategies in order to read efficiently.

Although the study provides substantial information about the use of reading strategies reported by EFL students, there was no clear evidence that the participants had finished assignments mechanically if they did not understand the reading materials. Therefore, it would be useful to have a future research work studying this case. Additionally, in replication, another pattern of reading strategy use may be discovered if a researcher will select other groups of students to participate in the future study; for example, students with different levels of English proficiency, students studying in different disciplines, and students having different cultural backgrounds. 


\section{ACKNOWLEDGMENT}

We would like to thank the Office of the Higher Education Commission, Thailand for supporting by grant fund under the program Strategic Scholarships for Frontier Research Network for the Joint Ph.D. Program Thai Doctoral degree for this study.

\section{REFERENCES}

[1] Adamson, H.D. (1990). ESL students' use of academic skills in content courses. English for Specific Purposes 9, 67-87.

[2] Adamson, H.D. (1991). Academic competence. English for Specific Purposes 5,55-79.

[3] Adamson, H.D. (1992). Academic competence: Theory and classroom practice. New York: Longman.

[4] Alderson, J. C. (2000). Assessing reading. Cambridge: Cambridge University Press.

[5] Ampra, K. \& Thaithae, C. (n.d). Thailand: Curriculum planning, development and reform. www.ibe.unesco.org/curriculum/Asia\%20Networkpdf/ndrepth.Pdf (accessed 15/1/2009).

[6] Anderson, N.J. (1991). Individual differences in strategy use in second language reading and testing. The Modern Language Journal 75.4, 460-472.

[7] Anderson, N.J. (1999). Exploring second language reading. Beijing: Foreign Language Teaching and Research Press.

[8] Bang, H.J. \& Zhao, C.G. (2007). Reading strategies used by advanced Korean and Chinese ESL graduate students: A case study. The Reading Matrix 7.1, 30-50.

[9] Block, E. (1986). The comprehension strategies of second language readers. TESOL Quarterly 20.3: 463-494.

[10] Brumfit, C. J. (1980). Problems and principles in English teaching. Oxford: Pergamon.

[11] Carrell, P.L. (1998). Can reading strategies be successfully taught? http://www.jalt-publications.org/tlt/files /98/mar/ carrell.html. (accessed 19/1/2009).

[12] Carrell, P.L. (1991). Strategic reading. In J.E. Alatis (ed.). Georgetown University Round Table on Language and Linguistics. Georgetown University Press.

[13] Goodman, K. (1995). The Reading Processes. In Carrell, Patricia L., and Eskey, David E., (eds.) Interactive Approaches to Second Language Reading. ( $6^{\text {th }} \mathrm{Ed}$.) Cambridge: Cambridge University Press, 11-12

[14] Grabe, W. (1991). Current development in second language reading research. TESOL Ouarterly 25.3, 375-406.

[15] Green, J. \& Oxford, R. (1995). A closer look at learning strategies, L2 proficiency, and gender. TESOL Quarterly 29.2, 261297.

[16] Intaraprasert, C. (2000). Language learning strategies employed by engineering students learning English at the tertiary level in Thailand. Ph.D. dissertation, The University of Leeds, England.

[17] Lau, K. (2006). Reading Strategy Use between Chinese Good and Poor Readers: A Think aloud Study. Journal of Research in Reading 29.4, 383-399.

[18] Li, S. and Munby, H. (1996). Metacognitive strategies in second language academic reading: A qualitative investigation. English for Specific Purposes 15.3, 199-216.

[19] Ministry of Education. (2002). The handbook for basic education: Foreign language curriculum, National Education Act 2001. Bangkok: Academic Department, Ministry of Education.

[20] Nunan, D. (1992). Research methods in language learning. Cambridge: Cambridge University Press.

[21] O’Malley, J.M. \& Chamot, A.U. (1990). Language strategies in second language acquisition. Cambridge: Cambridge University Press.

[22] Ozek, Y. (2006). A study on the use of cognitive reading strategies by ELT students. http://www.asianefljournal.com/pta_august_07_ozec.php. (accessed 9/12/2008).

[23] Pikulski, J. J. (1997). Teaching word-identification skills and strategies: balanced approach. http://www.eduplace.com/rdg /res/teach/def.html. (accessed 2/06/2005).

[24] Punch, K.F. (2005). Introduction to social research (2 $2^{\text {nd }}$ ed.). London: SAGE Publications Ltd.

[25] Sheorey R. \& Mokhtari, K. (2001). Differences in the metacognitive awareness of reading strategies among native and nonnative speakers. System 29.4, 431-449.

[26] Silapasatham, .(1999). The development of teachers of English in primary schools. Bangkok: The Office of the Education Council.

[27] Strauss, A. and Corbin, J. (1990). Basics of qualitative research: Grounded theory procedures and techniques. NP: Sage.

[28] Strauss, A., and Corbin, J. (1998). Basic of quantitative research: Techniques and procedures for developing ground theor $y\left(2^{\text {nd }}\right.$ ed.). Thousand Oaks, California: SAGE Publishers.

[29] Zhang, L.J. and Wu, A. (2009). Chinese senior high school EFL students' metacognitive awareness and reading Reading in a Foreign Language 21.1.: 31-59.

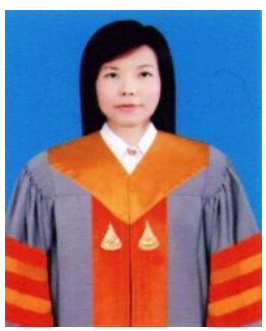

Rakchanok Saengpakdeejit is a Ph.D candidate in English Language Studies (ELS) at Suranaree University of Technology, Thailand. She has taught English courses at a university in Thailand. Her main research interests are language learning strategies and reading strategies. 


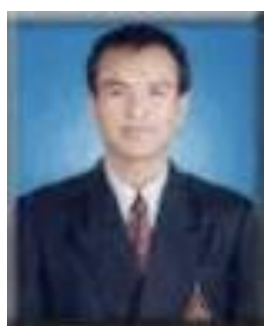

Channarong Intaraprasert (Ph.D) is an associate professor in TESOL at Suranaree University of Technology, Thailand. He has been teaching TEFL courses at different institutions in Thailand and Vietnam for more than 20 year. His main research interests are language learning strategies, and learner beliefs about language learning. 